\title{
Measurement and Analysis of Processing Costs in Academic Archives
}

\begin{abstract}
The timely processing of new acquisitions is essential to the successful management of academic archives and manuscript collections. Greater control of these activities may be accomplished through the measurement and analysis of processing costs. This paper proposes two procedures for costs studies and describes the results of such studies at the University of Illinois at UrbanaChampaign. It concludes with a description of processing efficiency measurements and suggestions for the application of study findings to program operations.
\end{abstract}

$\mathrm{T}$ HE PROCESSING of archival and manuscript collections is a central part of the operations of any college and university archives. Since processing accounts for a large share of personnel time, inefficiency in this area will adversely affect other aspects of academic archival programs. Success in reference service, preservation, appraisal, and full use of storage facilities all depend on the prompt and accurate processing of new collections. Because most academic archives face limitations on personnel resources, the ability to evaluate the efficiency with which they can process each new acquisition is in their interest. A clear understanding of staff resources required for processing will become even more important as increasing numbers of academic archivists face static or declining budgets. ${ }^{1}$

The efficiency of processing can be quantified, measured, and monitored through the use of cost analysis. While library literature provides several examples of cost analysis for acquisitions and cataloging of books, archivists have few examples relating to the processing of manuscript material. ${ }^{2}$ This lacuna probably results from archivists' perception that while library operations are identical from institution to institution, archival pro-

William J. Maher is assistant university archivist, University of Illinois at Urbana-Champaign. cessing involves the handling of unique material. Thus, the argument runs, measurement and quantification would not be worthwhile, since levels and standards of processing are dictated by the nature of each collection. They would not, therefore, be subject to efficiency or "cost/benefit" guidelines. This line of reasoning fails, however, when one realizes that the activities involved in processing are actually quite similar for many collections at most institutions, even though each collection is unique. Therefore, an analysis of a representative sample of processing can produce average cost and time measurements which can be used as guidelines for future processing operations.

This paper will demonstrate the use of cost analysis to measure the efficiency of processing archival and manuscript collections at an academic archives. It will suggest two methodologies for conducting a processing cost study and describe the results of such studies at the University of Illinois at UrbanaChampaign. To illustrate the relationship between the allocation of staff resources and the productivity of processing, this paper will propose three ways to measure processing efficiency.

Any cost study must depend on the collection and analysis of statistics for all the activities involved in processing. Undoubtedly, this will consume some of the archival manager's 
time, which could otherwise be devoted to appraisal, reference service, or more processing. However, analysis of processing is not only central to the archivist's administrative responsibilities, it also benefits the archival program in several areas. Information on the costs of and time spent processing records will help the archivist to establish guidelines to improve both the quality and quantity of processing; justify the budget and staff resources of the archives program; draft realistic grant proposals; and make better decisions about acquiring collections needing extensive processing. In academic archives where active collecting programs have resulted in the development of large backlogs of unprocessed material, a cost study may be the first step in eliminating the backlog.

Before proceeding, it is appropriate to define processing. "The Basic Glossary for Archivists and Manuscript Curators" (American Archivist 37:415-33 [July 1974]) describes processing as "the activities intended to facilitate the use of personal papers and manuscript collections generally comparable to arrangement, description, and preservation of archival material." This definition should be expanded to apply equally to official records as well as personal papers and manuscript collections. In its broadest sense, processing can include all procedures from the loading dock to final shelving and labeling of historical documents.

The complexity of these activities makes the measurement of processing costs quite difficult in any ongoing archival program. It is relatively easy to determine the cost of processing records handled as part of a grant project, since the project will have a defined budget and a readily discernible processing product at the completion of work. However, most college and university archives have no budget per se, and processing, records management, reference, and research functions are often performed by the same staff. In these situations, the archivist may determine processing costs by using one of two methodologies: retrospective analysis or direct measurement.

A retrospective study involves the analysis of annual report-type statistics to determine the volume of records processed and hours spent processing over a period covered by recent annual reports. This approach has been suggested by Maynard Brichford in a paper at the 1976 annual meeting of the Society of American Archivists. I elaborated on this method in a 1978 article in the Midwestern Archivist (V.3, no.2:3-24 [1978]), finding that the cost of processing a cubic foot of records at the University of Illinois during 1976-77 was about $\$ 19$.

The retrospective methodology has two prerequisites. First, a repository must maintain statistics on the annual volume of records processed and the total hours spent by archives personnel. Second, there must be a clear perception of what percentage of staff time is devoted to processing as opposed to research, reference, records management, or administrative duties. Once this information is available, we can determine the total cost of time spent processing. This figure is then divided by the volume processed in a given period in order to obtain a cost per cubic foot.

Internal studies at the University of Illinois have shown that professional staff (1.5 FTE) spends 20 percent of its time, and clerical staff (1 FTE) 5 percent of its time, in processing-related activities. ${ }^{3}$ The bulk of processing activity is performed by graduate student assistants and hourly student employees. The percentage of student time devoted to processing varies from year to year, but from July 1978 to June 1980 it averaged 63 percent for graduate students and 76 percent for undergraduates. During this same period of time, 1,115 cubic feet of records were processed. Staff resources devoted to this activity are illustrated in table 1 .

The total labor cost of $\$ 34,750.59$ can be divided by the total volume processed $(1,115)$ to arrive at a cost of $\$ 31.17$ per cubic foot. Since inflation and differences in hourly rates will limit the validity of this figure, it would be more useful to translate the cost into time to show that an average of 5.6 hours of labor were required for each cubic foot of processing.

Retrospective analysis of this type is both instructive and inexpensive if the appropriate statistics are available. The summary nature of this approach, however, permits only broad conclusions that must be used carefully. For example, precise costs for processing individual collections cannot be obtained because a retrospective analysis relies on estimates of the distribution of staff time. A po- 
TABLE 1

Retrospective Study: Measurement of Processing Costs From Annual Report Data, 1978-80

\begin{tabular}{lcccrr}
\hline \hline & $\begin{array}{c}\text { Average } \\
\text { Hourly Rate }\end{array}$ & $\begin{array}{c}\text { Total Hours } \\
1978-80\end{array}$ & $\begin{array}{c}\text { Percent } \\
\text { Time Spent } \\
\text { Processing }\end{array}$ & $\begin{array}{c}\text { Hours } \\
\text { Spent } \\
\text { Processing }\end{array}$ & $\begin{array}{c}\text { Cost of } \\
\text { Processing }\end{array}$ \\
\hline Professional staff (1.5 FTE) & $\$ 12.80$ & 5,424 & 20.0 & $1,084.8$ & $\$ 13,885.44$ \\
Clerical (1.0 FTE) & 6.80 & 3,808 & 5.0 & 190.4 & $1,294.72$ \\
Graduate students & 4.38 & 5,379 & 63.0 & $3,388.8$ & $14,842.94$ \\
$\begin{array}{l}\text { Undergraduates } \\
\text { Total }\end{array}$ & 3.07 & 2,013 & 76.0 & $1,539.9$ & $4,727.49$ \\
\hline
\end{tabular}

tentially more serious limitation is that a retrospective analysis does not account for processing variations that result from differences in the type of record or level of processing.

Many of these problems can be avoided by using a second methodology, direct measurement, which can establish the exact costs of processing each of several "representative" collections. This method requires gathering data on staff hours, volume processed, volume weeded, and pages of finding aids produced for each collection processed over a period of months. Once the work on several record series and manuscript collections is measured carefully, the archivist will be able to calculate average processing times and costs to use as guidelines in program planning and management. The University of Illinois archives conducted such a study for a tenmonth period in 1980 . The results are described below.

It should be noted that this method also has its disadvantages. It has occasionally been difficult to encourage processors, typists, and supervisory personnel to record time spent processing. In addition, this processing study has taken time that could have been spent in other activities. Nevertheless, the usefulness of this survey in planning the allocation of staff resources more than compensates for the time spent. Since direct measurement analysis need not be done continuously, a oneyear study should be more than adequate to provide a clear picture of processing activities.

The basic results of this study at the University of Illinois are contained in table 2.

These statistics, describing the processing of 309.2 cubic feet of records at the University of Illinois, reflect the nature of our holdings - administrative records and personal papers of an academic institution in the mid-twentieth century. They also are indica- tive of the inexpensive labor force we use for processing-part-time graduate students. While our cost figures may differ markedly from those at other institutions, they do reflect a labor force readily available to many academic archivists.

For this study, the specific processing activities included are weeding of duplicates and nonarchival material, writing and typing of descriptive finding aids, arrangement where necessary, and minor physical rehabilitation (removal of paper clips and rubber bands and some refoldering). Our finding aids include summary descriptions on fiveby-eight-inch control cards for all collections. Supplementary finding aids list folder titles for many collections larger than one cubic foot. About 45 percent of official records and 55 percent of personal papers have supplementary finding aids that average about half a typed page per cubic foot.

Certain staff activities have been excluded from this study because they are difficult to measure or fall outside our general definition of processing. These items include appraisal, records scheduling, boxing and shipping of records, and entry of descriptive coding data into an online automated system. The time spent by our civil service employee supervising typists is also not included.

Supplies are not included in this list because they generally account for only a small part of overall processing costs. In fact, supply costs are the easiest aspect of cost analysis for any repository to conduct. Table 3 details the cost of supplies used for the present study.

To a large extent, the data on processing staff time (table 2) are self-explanatory. They illustrate the total volume of records processed, time spent, and cost of staff. However, to be helpful in program planning and supervision of staff, there must be a way to use this data to develop measurements of processors' productivity and efficiency. The 
TABLE 2

Direct Measurement Study

Processing Costs, March-December 1980

\begin{tabular}{|c|c|c|c|c|c|c|c|c|c|c|c|c|}
\hline \multirow[b]{2}{*}{$\begin{array}{l}\text { Type of } \\
\text { Record }\end{array}$} & \multirow[b]{2}{*}{ Series ${ }^{*}$} & \multirow[b]{2}{*}{$\begin{array}{l}\text { Vol. } \\
\text { Proc. }\end{array}$} & \multirow[b]{2}{*}{$\begin{array}{c}\text { Products } \\
\text { Vol. } \\
\text { Weeded }\end{array}$} & \multirow[b]{2}{*}{$\begin{array}{c}\text { PP. } \\
\text { Finding } \\
\text { Aid }\end{array}$} & \multirow[b]{2}{*}{$\begin{array}{l}\text { Proc. } \\
\text { Prod. } \\
\text { Units }\end{array}$} & \multicolumn{4}{|c|}{ Staff Resources: Time and Costs } & \multicolumn{3}{|c|}{ Unit Costs/Hours } \\
\hline & & & & & & $\begin{array}{l}\text { Student } \\
\text { Processors } \\
(\$ 3.75 / \mathrm{hr})\end{array}$ & $\begin{array}{l}\text { Student } \\
\text { Typing } \\
(\$ 3.20 / \mathrm{hr})\end{array}$ & $\begin{array}{l}\text { Profes- } \\
\text { sional } \\
(\$ 12.80 / \mathrm{hr})\end{array}$ & $\begin{array}{c}\text { Total } \\
\text { Hours } / \\
\text { Cost }\end{array}$ & $\begin{array}{l}\text { Per } \\
\text { Cu. Ft. } \\
\text { Proc. }\end{array}$ & $\begin{array}{l}\text { Per Cu. } \\
\text { Ft. Proc. } \\
\& \text { Weeded }\end{array}$ & $\begin{array}{l}\text { Per Proc. } \\
\text { Product } \\
\text { Units } 1\end{array}$ \\
\hline $\begin{array}{l}\text { Office } \\
\text { records }\end{array}$ & 60 & 273.2 & 52.8 & 219 & 457.5 & $\begin{array}{l}824.5 \mathrm{hrs} \\
\$ 3,091.88\end{array}$ & $\begin{array}{c}106.35 \mathrm{hrs} \\
\$ 340.32\end{array}$ & $\begin{array}{l}35.25 \mathrm{hrs} \\
\$ 451.20\end{array}$ & $\begin{array}{l}966.1 \mathrm{hrs} \\
\$ 3,883.40\end{array}$ & $\begin{array}{l}3.5 \mathrm{hrs} \\
\$ 14.21\end{array}$ & $\begin{array}{l}3.0 \mathrm{hrs} \\
\$ 11.91\end{array}$ & $\begin{array}{l}2.1 \mathrm{hrs} \\
\$ 8.49\end{array}$ \\
\hline Personal & & & & & & $259.15 \mathrm{hrs}$ & $23.25 \mathrm{hrs}$ & $36.75 \mathrm{hrs}$ & $319.15 \mathrm{hrs}$ & $9.8 \mathrm{hrs}$ & $6.9 \mathrm{hrs}$ & $4.6 \mathrm{hrs}$ \\
\hline papers & 16 & 32.6 & 13.9 & 38 & 70.0 & $\$ 971.81$ & $\$ 74.40$ & $\$ 470.40$ & $\$ 1,1516.61$ & $\$ 46.52$ & $\$ 32.62$ & $\$ 21.67$ \\
\hline Publica- & & & & & & $10.5 \mathrm{hrs}$ & $2.5 \mathrm{hrs}$ & $6.0 \mathrm{hrs}$ & $19.0 \mathrm{hrs}$ & $5.6 \mathrm{hrs}$ & $1.8 \mathrm{hrs}$ & $1.4 \mathrm{hrs}$ \\
\hline tions & 15 & 3.4 & 6.9 & 3 & 13.8 & $\begin{array}{c}\$ 39.38 \\
1.094 .15 \mathrm{hrs}\end{array}$ & $\begin{array}{c}\$ 8.00 \\
132.1 \mathrm{hrs}\end{array}$ & $\begin{array}{l}\$ 76.80 \\
78.0 \mathrm{hrs}\end{array}$ & $\begin{array}{l}\$ 124.18 \\
304.25 \mathrm{hrs}\end{array}$ & $\begin{array}{l}\$ 36.52 \\
4.2 \mathrm{hrs}\end{array}$ & $\begin{array}{l}\$ 12.06 \\
3.4 \mathrm{hrs}\end{array}$ & $\begin{array}{l}\$ 9.00 \\
2.4 \mathrm{hrs}\end{array}$ \\
\hline Totals & 91 & 309.2 & 73.6 & 260 & 541.3 & $\$ 4,103.07$ & $\$ 422.72$ & $\$ 998.40$ & $\$ 5,524.19$ & $\$ 17.87$ & $\$ 14.43$ & $\$ 10.21$ \\
\hline
\end{tabular}

- Of the series listed here, 34 (16 official records, 7 personal papers, and 11 publications) were additions to existing series requiring no rewriting of control cards.

†Processing product units are equal to the total volume processed and weeded plus one-half unit for each page of finding aid or each control card written.

TABLE 3

Supply Costs, March-December, 1980

\begin{tabular}{|c|c|c|c|c|c|c|c|c|c|c|c|c|c|}
\hline \multirow{2}{*}{$\begin{array}{l}\text { Type of } \\
\text { Record }\end{array}$} & \multirow{2}{*}{$\begin{array}{c}\text { Number } \\
\text { of } \\
\text { Series }\end{array}$} & \multirow{2}{*}{$\begin{array}{l}\text { Volume* } \\
\text { (Cu. Ft.) }\end{array}$} & \multicolumn{2}{|c|}{$\begin{array}{l}\text { Document } \\
\text { Letter }\end{array}$} & \multicolumn{2}{|c|}{$\begin{array}{c}\text { Boxes } \uparrow \\
\text { Document } \\
\text { Legal }\end{array}$} & \multicolumn{2}{|c|}{$\begin{array}{l}\text { Records } \\
\text { Center }\end{array}$} & \multirow{2}{*}{$\begin{array}{c}\text { Aver. } \\
\text { per } \\
\text { Cu. Ft. }\end{array}$} & \multirow{2}{*}{$\begin{array}{c}\text { Folders } \uparrow \\
\text { No. }\end{array}$} & \multirow[b]{2}{*}{ Cost } & \multirow{2}{*}{$\begin{array}{c}\text { Total Cost } \\
\text { of } \\
\text { Supplies }\end{array}$} & \multirow{2}{*}{$\begin{array}{l}\text { Average } \\
\text { Cost per } \\
\text { Cu. Ft. }\end{array}$} \\
\hline & & & No. & Cost & No. & Cost & No. & Cost & & & & & \\
\hline Office & & & & & & & & & & & & & \\
\hline $\begin{array}{l}\text { Records } \\
\text { Personal }\end{array}$ & 60 & 273.2 & 134 & $\$ 171.52$ & 2 & $\$ 2.72$ & 223 & $\$ 127.11$ & 4.5 & 1,229 & $\$ 115.53$ & $\$ 416.88$ & $\$ 1.53$ \\
\hline Papers & 16 & 32.6 & 26 & $\$ 33.28$ & 1 & $\$ 1.36$ & 24 & $\$ 13.68$ & 15.3 & 499 & $\$ 46.91$ & $\$ 95.23$ & $\$ 2.92$ \\
\hline $\begin{array}{l}\text { tions } \\
\text { Totals }\end{array}$ & $\begin{array}{l}15 \\
91\end{array}$ & $\begin{array}{r}3.4 \\
309.2\end{array}$ & $\begin{array}{r}8 \\
168\end{array}$ & $\begin{array}{l}\$ 10.24 \\
\$ 215.04\end{array}$ & $\begin{array}{l}1 \\
4\end{array}$ & $\begin{array}{l}\$ 1.36 \\
\$ 5.44\end{array}$ & $\begin{array}{r}0 \\
247\end{array}$ & $\begin{array}{r}0 \\
\$ 140.79\end{array}$ & $\begin{array}{l}1.2 \\
5.6\end{array}$ & $\begin{array}{r}4 \\
1,732\end{array}$ & $\begin{array}{l}\$ .38 \\
\$ 162.82\end{array}$ & $\begin{array}{l}\$ 11.98 \\
\$ 524.09\end{array}$ & $\begin{array}{l}\$ 3.52 \\
\$ 1.69\end{array}$ \\
\hline
\end{tabular}

-The total capacity of the boxes used in about 4 cubic feet less than the total volume processed. This is because some of the material processed as additions to existing collections was placed in the same boxes a previously processed material.

TDocument boxes used are from Hollinger Corporation: letter size (.3 cu. ft.) at $\$ 1.28$ each; legal size (.4 cu. ft.) at $\$ 1.36$ each (1979). Record center boxes hold 1.0 cubic foot, and were purchased from Eastex Mfg. in Madison, Wisconsin, in 1980 for 57 cents each. Folders were purchased from Hollinger Corporation in 1979 for 9.4 cents each. 
table lists three such measurements.

The first measurement, cost per cubic foot processed, is obtained by dividing the cost (or hours) of processing by the final volume of the processed collection. This results in an average of $\$ 17.87$ (or 4.2 hours) per cubic foot. Archivists can use this measurement to compare costs of processing different types of records. In the present study, for example, processing personal papers costs three times more than processing official records.

This formula, however, cannot provide a complete measure of productivity, because it does not account for the volume of duplicate and nonarchivat material weeded in the course of processing. Therefore, a second type of unit cost should be calculated by dividing the cost (or time) of processing by the total volume processed and weeded (i.e., the original volume of the unprocessed material). In the present sample, this averaged $\$ 14.34$ (or 3.4 hours) per cubic foot. By accounting for the reduction in volume through weeding, the archivist can obtain a more realistic measure of productivity since weeding, even though it requires considerable time, also benefits archival programs through a savings of storage space.

Because these two measures do not acknowledge the significant amount of time devoted to description, table 2 contains a third measurement of efficiency - the cost (and time) per processing product unit. This is derived from the volume processed and weeded as well as from the writing of control cards and finding aids. On the basis of a study of a sample group of series at the University of Illinois, it was determined that the time required for producing one page of a finding aid or one control card was 1.7 hours, whereas the time spent to produce one cubic foot of processing or weeding was 3.1 hours. For the purposes of rough comparison, the figures were rounded so that one processing product unit could be assigned to each cubic foot processed or weeded, and one-half unit could be assigned to each control card or finding-aid page written.

Once the processing product units for a series have been calculated, their total can be divided into the cost (or time) of processing to determine the cost or time required for each of the processing products. In the current study, the cost per product unit averaged
$\$ 10.21$ (or 2.4 hours) per product unit.

The cost per product unit permits the evaluation of the major output of processors and compensates for discrepancies in cost figures that can occur if a great deal of time is spent on detailed finding aids. Archivists, however, should be cautious about broadly adopting the actual measurement described above, since the assignment of the unit values in this paper is based on a relatively narrow sample. Each institution must determine its own unit values based on its own processing standards. It should also be remembered that most processors perform several functions simultaneously, thus it is not always possible to separate clearly the time spent describing from the time spent arranging or rehabilitating files. Within these limits, however, the cost per processing product unit approach permits useful comparisons to determine the efficiency of processing staff.

Several conclusions are evident from the data presented in table 2. The fact that official records take less time to process than personal papers is not surprising since official records generally arrive in the archives in reasonably good order with clearly marked folder labels, whereas personal papers are frequently disorganized and contain items not in folders or in unmarked folders. Moreover, personal papers frequently contain documents on disparate subjects and therefore require more time for description.

These data also show that the processing of university publications is expensive and timeconsuming if the final processed volume alone is considered. This is because such processing involves sorting the printed matter according to office of origin, identifying the record series to which the given item belongs, weeding duplicates, filing the item, and making changes in control cards and boxes when necessary. In most cases, such processing is not necessar to write finding aids or new control cards for publications. The large amount of time spent, however, should be seen in light of the amount of space saved through weeding and the access provided through description. In this case, the value of using the cost per processing product unit measurement, instead of the cost per cubic foot measurement, is evident.

At this point, it is appropriate to compare the results of the retrospective analysis (table 


\section{4 / College b Research Libraries • January 1982}

1) to the direct measurement study (table 2). While there is a discrepancy between the two studies regarding time required for processing a cubic foot ( 4.2 hours for the direct measurement and 5.6 hours for the retrospective analysis), the difference of 1.4 hours per cubic foot is not excessive. The discrepancy is mainly the result of processing a higher ratio of official records (which require less time) during the direct measurement than during the retrospective analysis. During the direct measurement study, the ratio was 88.4 percent official records, 10.5 percent personal papers, and 1.1 percent publications. During the two years covered by the retrospective study, the ratio was 64.2 percent official records, 30.2 percent personal papers, and 5.6 percent publications. This predominance of office records explains why the direct measurement study resulted in a lower average processing time than did the retrospective study.

While the sample used for the direct measurement study is less representative of the archives' holdings of different types of records, this study's findings are more useful because they differentiate processing activities by type of record. The most useful data in table 2 are those that reflect the average time for processing, weeding, and describing each of the three different types of records. This information permits the development of more precise guidelines to schedule and supervise staff. In fact, if series-by-series data are retained, they can be a reference point when assigning staff to process new collections that appear similar to those done during the direct measurement study.

Another way in which the direct measurement study can improve control of processing operations is the use of its findings on distribution of time by type of staff and activity. This information can assist the archivist in allocating personnel resources and developing realistic schedules. For example, table 2 illustrates that the largest amount of processing time at the University of Illinois was that of student employees (about 94 percent). Thus a large share of processing was being performed by a relatively inexpensive labor force.

To obtain a more precise view of the distribution of processing time and costs, a sample of thirty-two record series was analyzed in closer detail. This sample is based on those series for which it was possible to obtain separate statistics on basic components of processing-arrangement, description, and preservation. These thirty-two series (thirty office records, one personal papers, and one publication) had a processed volume of 71 cubic feet, a weeded volume of 17.4 cubic feet, 95 finding aid pages, and 28 new control cards, for a total of 149.9 processing product units. For purposes of comparisons, the total processing cost was $\$ 1,953$, or $\$ 27.51$ per cubic foot processed, or $\$ 22.09$ per cubic foot processed and weeded, or $\$ 13.03$ per processing product unit. This translates into a total of 487.5 hours ( 6.9 hours per cubic foot processed, 5.5 hours per cubic foot processed and weeded, or 3.3 hours per processing product unit). Figure 1 shows the distribution of staff time and activities for these series.

In this sample, professional staff accounted for a smaller part of the processing costs (only 10.8 percent) than in the overall study (18.1 percent). The breakdown of supervisory time (figure 1, B) is interestingthe greatest amount of time (58.3 percent) was spent in determining provenance and assigning the proper series number to each group of records. Description also required a substantial portion of supervisory time because concise descriptions of record series were necessary to simplify research access. The remaining portion of supervisory time was spent advising processors on problems of internal arrangement, level of description, and identification of documents.

Figure 1, C shows that, for this sample, description was the single most timeconsuming activity involved in processing. Arrangement, weeding, and rehabilitation each occupied equal amounts of time. Internal arrangement is frequently necessary even for well-structured office records because office staff and physical-plant personnel often disturb the original order when transferring files from cabinets to boxes. Weeding and rehabilitation include the removal of paper clips, rubber bands, and other harmful substances, and the replacement of some folders. At the University of Illinois, it does not include extensive treatment of documents, e.g., deacidification, lamination, or encapsulation.

It is unlikely that the percentages shown in 
A

Processing Costs

(by Type of Staff)

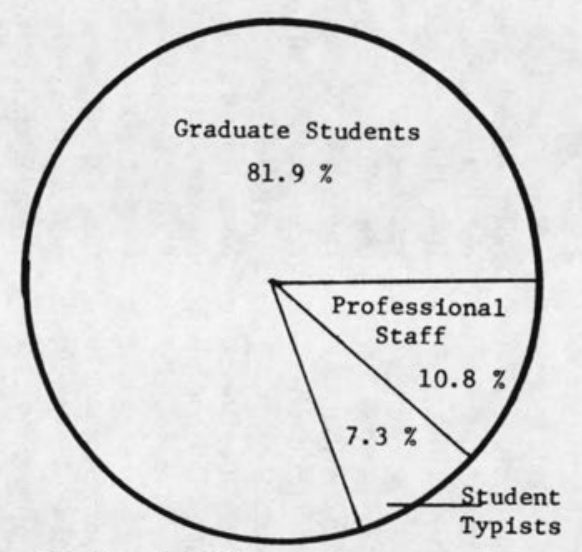

B

Supervision (by Type of Activity of Professional Staff

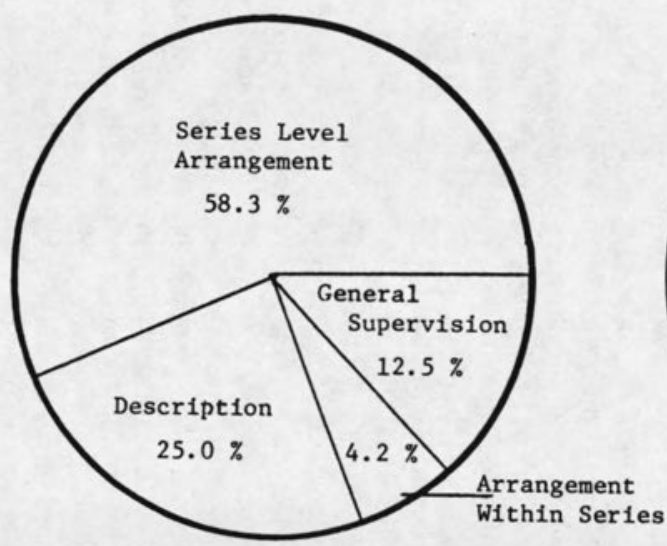

C

Processing Time-Professional and Graduate Student Staff

(by Type of Activity)

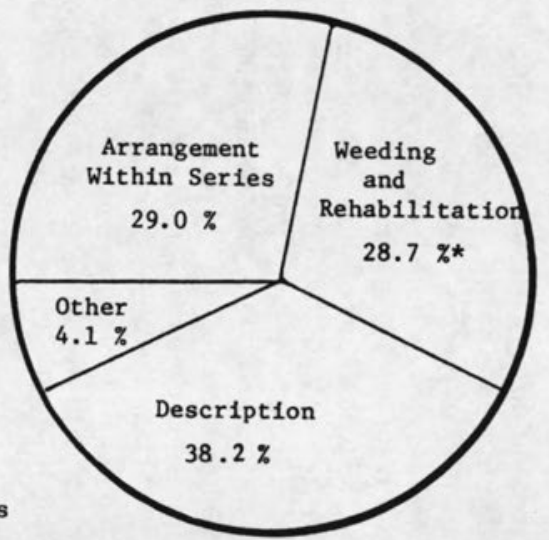
deacidification or encapsulation inction.

Distribution of Costs, Staff Time, and Activities 
these pie graphs will correspond directly to figures for processing at other institutions. In addition, any statistical summary of processing time and costs cannot do justice to the wide variation from series to series. These variations occur because of the physical condition and arrangement of the records; the skill, experience, and speed of the processor; and the research value of the material. For example, a well-arranged alphabetical subject file can be processed quite quickly by an experienced staff member, whereas a collection of faculty papers with unlabeled folders documenting several subjects will require considerably more time even if processed by an experienced professional.

The experience and education of the individual processor is, then, most important. For example, an anthropology graduate student is likely to be a more efficient processor for personal papers of anthropologists than an engineering student (provided the student does not become too absorbed in the material and read every document). Indeed, this survey found that processors with the longest tenure were generally the most efficient and best workers. Ideally, all processing should be performed by the professional staff because the speed and quality of its work are higher. This compensates for their much higher hourly wage. However, most academic archives do not have enough professional staff members to do all of the processing. The use of graduate and undergraduate students for processing, therefore, represents a realistic alternative to developing large backlogs of unprocessed material.

Most archivists will not be surprised by these conclusions and they might, therefore, question the value of doing such a detailed study of processing costs. Indeed, many of the findings of this University of Illinois study may have merely confirmed the assumptions that have guided our work in the past. Nevertheless, the study has provided a quantitative basis on which to analyze the productivity of staff members. Most important, it has suggested a way to arrive at average processing time figures so that we can establish realistic criteria for the performance of our work.

Practical application of these studies covers a broad range of archival work from appraisal to reference access. However, it would be inadvisable to use processing statis- tics as the sole basis for administering a program. To determine the level of description or collecting scope primarily on cost/benefit considerations would be an inappropriate use of this study. Rather, the results of processing cost studies can provide background for many important administrative decisions. For example, time and cost estimates can provide a statistical basis for seheduling transfers of records and solicitations of faculty papers or manuscript collections so that processing backlogs are kept to a minimum. If processing-time estimates show that a prospective acquisition would strain the archives resources, these same data can be used to develop proposals for more staffing. Knowledge of processing time and costs can guide the archivist in determining the length and types of finding aids to provide access to collections without overburdening the staff. Finally, the results of cost studies can lay the foundation for further research into methods for improving the productivity and quality of processing, such as dividing large collections between several processors or having some processors specialize in arrangement and others in description.

Many archivists may be skeptical of the value of cost studies in general. This analysis of processing at the University of Illinois is presented in full realization that each record series or manuscript collection is unique and that each processor has distinctive work habits. Each repository has different standards for processing, and the research possibilities of each collection can dictate vastly different levels of processing. For this reason each institution should develop its own data for use in the models presented above.

It is hoped that this study will serve as a catalyst for similar studies at other universities. The fact that Illinois' results of $\$ 17.87$ per cubic foot contrast sharply with those cited elsewhere illustrates the need for more studies so we can determine what factors cause such variations. ${ }^{4}$

The inherent diversity of the archival profession helps explain the differences in processing costs from one institution to another. Variations also result from most archivists' individualistic approach to reporting data in that variations in the types of statistics used will result in differences in processing statistics at each institution. Therefore, a crucial 
step for further research will be the development of greater uniformity in reporting statistics. The recently appointed Society of American Archivists' Task Force on Standard Reporting Practices should be a step in this direction. Archivists should not, however, wait for the task force's final report before proceeding with analysis of processing costs.

Archivists who have maintained statistics on processing activities for several years are in an excellent position to begin retrospective studies immediately. Others may prefer direct measurement studies, which require collection of data for only a limited time period. College and university archivists should not hesitate to use these techniques to determine the efficiency of their programs. The small amount of time required for these studies will be well spent because they can lead to improvements in the quality and quantity of work. Archivists will then be in a better position to plan for the future and prepare for the consequences of declining, static, or expanding budgets. Moreover, techniques developed in these studies may provide models for financial analyses of many archival activities, such as preservation or reference. These self-studies are necessary if archivists wish to improve administrative control of their programs.

\section{REFERENCES}

1. An earlier study of processing costs was discussed in a speech at the 1980 annual meeting of the Society of American Archivists. A transcript of the speech is available from the SAA as part of its Problems in Archives Kit 4, "Archival Processing Costs."

2. For example: Anton R. Pierce, Joe K. Taylor, "A Model for Cost Comparison of an Automated Cataloging System," Journal of Library Automation 11:6-23 (March 1978); Dennis R. Elchesen, "A Cost Effectiveness Comparison of Manual and On-line Retrospective Bibliographic Searching," American Society for Information Science Journal 29:56-66 (March 1978). The January 1972 issue of Library Quarterly contained several articles on "operations research" and its application to library activities. One of these articles, "Library Objectives and Performance Measures and Their Use in Decision Making” (p.107-28), suggested that statistical analysis of library operations should be connected to a calculation of cost/benefit ratios. One of the few examples in archival literature of an awareness of the necessity for cost analysis may be found in Michael Cook's Archives Administration (Folkstone, Kent: Wm. Dawson and Sons, 1977). W. N. Davis' "Budgeting for Archival Processing," American Archivist 43:209-11 (Spring 1978), reports on a processing cost study performed at the California State Archives. However, it provides little insight into the methodology or purpose of the study.

3. William J. Maher, "The Importance of Financial Analysis of Archival Programs," Midwestern Archivist 3, no. 2:8 (1978).

4. A study conducted in New Zealand by Thomas Wilsted, for example, showed a cost of U.S. \$49 per cubic foot to process manuscripts collections at the Alexander Turnbull Library. (Wilsted's findings were N.Z. $\$ 132$ per linear meter. This was converted, for comparison's sake, to $2.6 \mathrm{cu}$ bic feet per linear meter, and N.Z. \$1 equaled about U.S. $\$ .96$ at the time of his study.) Thomas Wilsted, "Scoring Archival Goals" in Andrew Lemon, ed., Archives Conference Proceedings 1977 (Australian Society of Archivists, 1978), p.19-29. 